\title{
Disponibilidad de las técnicas constructivas de habitación en madera, en Brasil
}

\author{
Availability of timber housing construction techniques in Brazil \\ Disonibilidade das técnicas construtivas de moradia em madeira no Brasil
}

\section{Victor A. De Araujo}

Grupo de Investigación LIGNO, Itapeva (Brasil)

Carlos M. Gutiérrez-Aguilar

Instituto Tecnológico Metropolitano (ITM), Medellín

(Colombia)

\section{Juliana Cortez-Barbosa}

Maristela Gava

Universidad Estadual Paulista (UNESP), Itapeva (Brasil)

José N. Garcia

Universidad de São Paulo (USP), Piracicaba (Brasil)

De Araujo, V. A., Gutiérrez-Aguilar, C. M., Cortez-Barbosa, J., Gava, M., \& Garcia, J. N. (2019). Disponibilidad de las técnicas constructivas de habitación en madera, en Brasil. Revista de Arquitectura (Bogotá), 2/(I), 68-75. doi: http://dx.doi.org/10.14718/RevArq.2019.21.1.2014

\section{(c) $(1) \Theta$}

\author{
Victor A. De Araujo \\ Ingeniero industrial maderero, Universidad Estadual Paulista, Itapeva (Brasil). \\ Doctor en Ciencias Forestales, Universidad de São Paulo, Piracicaba (Brasil). \\ http://www.researchgate.net/profile/Victor_De_Araujo \\ (D) http://orcid.org/0000-0002-2747-4738 \\ engim.victor@yahoo.de \\ Carlos M. Gutiérrez-Aguilar
}

Diseñador industrial, Pontificia Universidad Javeriana, Bogotá (Colombia)

Maestro en Dirección de Proyectos, Universidad de Viña del Mar, Viña del Mar (Chile).

Doctorando en Ingeniería Industrial, Universidad Federal de Bahia, Salvador (Brasil). (D) http://orcid.org/0000-0002-6975-4789

carlosgutierrez@itm.edu.co

Juliana Cortez-Barbosa

Arquitecta y urbanista, Pontificia Universidad Católica, Campinas (Brasil).

Maestra en Arquitectura y Urbanismo, Universidad de São Paulo, São Carlos

(Brasil).

Doctora en Ciencias Ambientales, Universidad de São Paulo, São Carlos (Brasil). (D) http://orcid.org/0000-0003-0006-7945

jucortez@itapeva.unesp.br

Maristela Gava

Arquitecta y urbanista, Universidad Federal de Espirito Santo, Vitória (Brasil).

Maestra en Arquitectura y Urbanismo, Universidad de São Paulo, São Carlos (Brasil).

Doctora en Ciencias Forestales, Universidad de São Paulo, Piracicaba (Brasil).

(D) http://orcid.org/0000-0003-0054-5927

mgava@itapeva.unesp.br

José N. Garcia

Ingeniero forestal, Universidad de São Paulo, Piracicaba (Brasil)

Ingeniero civil, Escuela de Ingeniería de Piracicaba, Piracicaba (Brasil).

Maestro en Ingeniería de Estructuras, Universidad de São Paulo, São Carlos (Brasil). Doctor en Ingeniería de Estructuras, Universidad de São Paulo, São Paulo (Brasil). Posdoctorado en Ingenierías, Universidad Henry Poincaré, Nancy (Francia).

(D) http://orcid.org/0000-0002-8289-9042

ingarcia@usp.br

\section{Resumen}

Se analiza la representatividad de las viviendas hechas en madera, en Brasil, indicando el porcentaje de cada técnica constructiva según la oferta de las empresas evaluadas. Los porcentajes que evidencian la frecuencia de utilización de las técnicas de construcción en madera fueron medidos por medio de dos metodologías aplicadas en las empresas: encuesta por entrevistas personales a sus propietarios y búsqueda de datos en sus sitios web. El método de encuestas por entrevistas evaluó 107 empresas brasileñas, y el de búsqueda en los sitios web alcanzó 207 empresas; se consiguió 50,95 y 98,57\%, respectivamente, de la población estimada. A pesar de esta diferencia, ambos métodos demostraron un escenario similar. Las entrevistas presentaron mayores costos de aplicación. Las técnicas contemporáneas están disponibles en más del $90 \%$ de los productores brasileros. Las casas de tablas horizontales clavadas y las casas de tablas horizontales entre pilares fueron las que tuvieron mayores ofertas.

Palabras clave: arquitectura brasileña en madera; estructuras de madera; material vegetal; materiales de construcción; sistemas constructivos; vivienda en madera.

\section{Abstract}

This paper analyzes the representativeness of timber housing in Brazil, identifying the percentage of construction techniques offered by each evaluated company. Percentages that evidence the frequency of use of wooden building techniques were measured using two methods applied in the companies: survey through face-to-face interviews with owners and data search on their websites. The survey through interviews evaluated 107 Brazilian companies, while the data search included 207 companies, obtaining $50.95 \%$ and $98.57 \%$ of the estimated population, respectively. In spite of this difference, both methods showed a similar scenario. Interviews evidenced higher application costs. Contemporary techniques are available in more than $90 \%$ of Brazilian constructors. Houses with nailed horizontal boards and houses with horizontal wooden boards between columns were offered the most.

Keywords: Timber architecture in Brazil; wood structures; plant materials; construction materials; construction systems; timber housing.

\section{Resumo}

Neste artigo, é analisada a representatividade das moradias feitas em madeira no Brasil por meio da indicação da porcentagem de cada técnica construtiva segundo a oferta das empresas avaliadas. As porcentagens que evidenciam a frequência de utilização das técnicas de construção em madeira foram medidas mediante duas metodologias aplicadas nas empresas: entrevistas pessoais a seus proprietários e busca de dados em sites. O método de entrevistas pessoais avaliou 107 empresas brasileiras, e a busca nos sites atingiu 207 empresas; foram alcançados 50,95 e 98,57\%, respectivamente, da população estimada. Apesar dessa diferença, ambos os métodos demonstraram um cenário semelhante. As entrevistas apresentaram maiores custos de aplicação. As técnicas contemporâneas estão disponíveis em mais de $90 \%$ dos produtores brasileiros. As casas de tábuas horizontais pregadas e as casas de tábuas horizontais entre pilares foram as que mais tiveram ofertas.

Palavras-chave: arquitetura brasileira em madeira; estruturas de madeira; material vegetal; materiais de construção; sistemas construtivos; moradia em madeira. 


\section{Introducción}

Este artículo se deriva de la amplia investigación "Viviendas de madera y el potencial de producción en Brasil", la cual está adscrita a la línea de investigación en "Construcciones en materiales lignocelulósicos" del Grupo de Investigación LIGNO. Este diagnóstico sectorial es liderado por el primer autor con soporte directo de los autores de este artículo y de otros actores profesionales y académicos, bajo la orientación principal del último autor. Toda la investigación fue realizada y financiada con recursos propios del primer autor entre 2013 y 2017, exclusivamente por aportes procedentes de su beca de Doctorado-Directo en Ciencias de los Recursos Forestales, en el área de Tecnología de Productos Forestales, para su respectivo Programa de Posgrado de la Escuela de Agricultura "Luiz de Queiroz" de la Universidad de São Paulo.

El enfoque de la investigación base de este y de otros artículos (De Araujo et al., 2018) se centró en la realización de un diagnóstico para identificar y caracterizar los principales aspectos y el panorama actual del sector productivo de viviendas en madera en Brasil, explorando las potencialidades de la madera y de las casas producidas con este material constructivo sostenible y renovable. Para este artículo se estudió la disponibilidad de cada técnica habitacional en madera presente en las empresas evaluadas, comparando dos métodos de recolección de datos: búsqueda en sitios web y entrevistas personales.

Calil Júnior y Dias (1997) contemplaron que la madera hace parte del progreso de la humanidad desde las edades de Piedra, Hierro y Broce, lo que revela su gran importancia para la existencia de la civilización. Neufert y Neff (2013) resaltan que una vivienda en madera maciza es esencialmente la forma de vivir más natural, original y saludable. De acuerdo con Martínez-Osorio, Barana, Rocha-Carneiro y Paschoarelli (2017), el procesamiento de la madera está presente en las diferentes cadenas productivas. Shimbo e Ino (1997) refuerzan que la madera permite el montaje de componentes prefabricados, así como el uso intensivo de mano de obra y baja inversión en bienes de capital. Teniendo en cuenta el orden cronológico propuesto por Mello (2007), los sistemas de habitación en madera son identificados como tradicionales (clásicos) o contemporáneos (modernos), los cuales fueron claramente discutidos e ilustrados por esquemas y figuras en Benoit y Paradis (2008), Ching (2010), Morgado, Guedes, Ferreira y Cruz (2012), Neufert y Neff (2013) y De Araujo et al. (2016b).

\section{Métodos constructivos tradicionales en madera, en Brasil}

Los inmigrantes europeos aprovecharon la disponibilidad de recursos materiales locales en Brasil para obtener rapidez y facilidad constructiva, y crearon un lenguaje propio capaz de expresar una cultura arquitectónica local y una amplia variedad de diseños (Zani, 2013); la producción forestal permitió a la madera posicionarse entre las materias primas más populares, lo que estimuló su uso en la construcción en el siglo XIX. Lessa y Silva (2003) afirman que una producción de casas de madera maciza adaptadas a las condiciones locales puede resolver las necesidades de vivienda, a pesar de las limitaciones del material.

Debido a esta inserción cultural promovida por los primeros inmigrantes, Brasil absorbió buena parte de sus técnicas de construcción en madera. De Araujo et al. (2016a) apuntan que, aun con una industrialización lenta en la mitad del siglo XX, varias madereras se enfocaron en la producción de casas prefabricadas.

Un fuerte indicio de esta situación remite al hecho de que, hasta la mitad del siglo XX, la arquitectura en madera fue muy marcada y predominante en los paisajes del estado de Paraná (Zani, 2013). La construcción de casas de madera surge como la alternativa más viable para sustituir la albañilería, debido a los buenos atributos de racionalización de la materia prima, producción libre de uso de agua, limpieza de la obra y producción rápida y eficiente (De Araujo et al., 2016d). En su esencia, una casa de madera tradicional se hace artesanalmente con máquinas y herramientas simples, no obstante, también puede ser obtenida de procesos industriales que permiten el montaje en la obra.

Las técnicas constructivas tradicionales a base de maderas hechas en Brasil son: casas de troncos, casas de estructura mixta en madera y albañilería, y casas de tablas y tapajuntas.

La casa de troncos es denominada en inglés log-home, y consiste en un sistema constructivo basado en el apilamiento de piezas de madera (rústica, rolliza o aserrada), que actúa de modo portante, o sea, la estructura y el cerramiento actúan en un mismo elemento estructural. A pesar de la posibilidad de orientación vertical, Kretschmann (2010) indica que el modelo horizontal de las piezas se traduce en mejores condiciones térmicas y estructurales. Neufert y Neff (2013) indican que los troncos o las tablas sobrepuestas son estructuralmente interconectas por uniones de encaje o ranuras, populares en el hemisferio norte.

También designado por el termino francés colombage o el alemán fachwerk, la casa de estructura mixta en madera y albañilería es muy popular en Francia y Alemania. Consiste en la principal técnica constructiva de carácter mixto, por emplear la madera como estructura sólida en conjunto con la albañilería (ladrillos de barro, adobes, piedras, bloques de cemento, etc.) como cerramiento de las paredes. Weimer (2005) enfatiza que un importante aspecto de este proceso constructivo es la ausencia de clavos o tornillos en su estructura. Tosolini (2008) apunta que esta técnica es muy utilizada en construcciones rurales. 
Kniffen y Glassie (1966) señalan que este proceso es hecho con bloques verticales, normalmente apoyados entre sí, con los espacios del cuadro de madera rellenados con varios materiales. Benoit y Paradis (2008) subrayan que los pilares estructurales son continuos de piso a techo.

La casa de tabla y tapajuntas está formada por un cerramiento vertical de tablas de madera paralelas ligeramente espaciadas, cuyos espacios son cerrados por reglas denominadas tapajuntas. Imaguire Junior e Imaguire (2011) avalúan que esta estructura es caracterizada por la textura externa vertical, fabricada con la madera de Pinus spp. De Araujo et al. (2016b) indican que estas casas son de origen eslavo y son populares en las regiones sur y sureste de Brasil. Szücs y Batista (2007) señalan que estas construcciones poseían una complejidad tipológica ecléctica y no presentaban barreras sociales, es decir, eran accesibles a ricos y pobres.

\section{Métodos constructivos contemporáneos en madera, en Brasil}

Con el avance tecnológico se desarrollaron varias herramientas eléctricas para facilitar el trabajo con la madera (De Araujo et al., 2015, 2016c, d). Según Novas-Cabrera (2010), la industrialización de la construcción presentó un profundo avance como resultado de la Primera Guerra Mundial, por cuenta de la escasez de mano de obra y materiales, lo que aumentó los costos, por lo que se desarrolló la prefabricación para reducir el costo elevado del trabajo.

El estilo moderno en madera incluye los modelos constructivos más recientes de la era industrial, en virtud del uso de componentes producidos desde la prefabricación de la madera maciza hasta la producción de vigas y paneles de madera de alta resistencia estructural. A pesar de esa innovación, los ejemplos modernos pueden incluir producciones más artesanales.

Las técnicas constructivas contemporáneas en madera hechas en Brasil son: casas de tablas horizontales entre pilares, casas de doble pared con tablas clavadas, entramado pesado, casas de palillero con albañilería, woodframes, modular (CLT y zona de obras) y casa móvil.

Las casas de tablas horizontales entre pilares se refieren al sistema constructivo con paredes portantes de planchas encajadas entre sí con rebajas y trabadas en cada extremidad por montantes de madera con rasgos de canal (De Araujo et al., 2016b). César (2002) define que estas son utilizadas como casas de veraneo (playa y campo) y chalets. Producidas en kits prefabricados, Casema (1998) apunta que poseen elementos encajables en madera verde, cuyas paredes sufren acomodaciones durante el montaje y la ocupación inicial.

Las casas de doble pared con tablas clavadas son popularmente empleadas en chalets y casas de paseo. A pesar de su rusticidad, estos ejemplos poseen cierto grado de prefabricación. Esta técnica posee paredes formadas por una estructura liviana de madera aserrada revestida por dos caras de tablas clavadas, interna y externamente. Esta técnica es definida conforme a la orientación externa de las tablas, es decir, vertical o horizontal. De Araujo et al. (2016b) señalan que las tablas externas son orientadas horizontalmente, en cuanto que el cerramiento interno posee disposición vertical, lo que genera un acabado diferente.

El entramado pesado es una técnica compuesta por una robusta y rígida estructura (pórtico) en madera cerrada con una solución no estructural de vidrio o de madera. Ching (2010) apunta que este sistema de construcción utiliza una trama de elementos verticales (pilares) y horizontales (vigas) para transferir las cargas de cobertura y piso. Wacker (2010) indica que un pilar-viga tradicional está hecho por grandes bloques de madera conectados entre sí por uniones fabricadas manualmente como "ranura y espiga", que exigen un trabajo de carpintería sofisticado. De acuerdo con Presnitz (2009), el pilar-viga es un sistema simple y elegante, pues se compone de grandes postes y vigas de madera que se encajan en conjunto. Charles y Charles (1984) señalan que la estructura autoportante se refiere a la tecnología constructiva cuyas paredes exteriores son capaces de soportar el peso de la cobertura, además de contener elementos secundarios, esto es, puertas, ventanas, paneles y revestimientos.

Paralelamente, el mercado brasilero presentó una variación nacionalizada del pilar-viga denominada "palillero". Esta versión se basa en la rusticidad estética, quiere decir, sin ningún ornamento o ranuras decorativas. Por otro lado, el palillero utiliza uniones entre elementos estructurales por conexiones metálicas, tanto clavos como tornillos. Tal variación prioriza el empleo de maderas de bosques cultivados, en general especies no nativas, como el eucalipto o el pino. A pesar de la posibilidad, el uso de maderas nativas para esta técnica no es algo común.

El woodframe, también denominado entramado ligero de madera, consiste en un sistema constructivo provisto de un cuadro estructural de madera con piezas de secciones cortas, cuyo cerramiento interno y externo es realizado por paneles de madera estructurales unidos por clavos galvanizados. Un woodframe puede ser clasificado como globo, plataforma, mixto o también por su versión moderna e industrializada, denominada modular. Ching (2010) subraya que el woodframe globo utiliza montantes que se elevan a la altura total de la estructura, de la viga del umbral hasta la viga de la cobertura, con barrotes clavados en los montantes junto a los travesaños fijados para su sustentación. Wagner (2009) resalta que el woodframe plataforma es eficiente para casas multipavimiento, pues se basa en plataformas montadas de manera independiente para cada piso, al contrario del variante globo, 
cuya estructura es hecha una única vez, debido a los componentes estructurales más robustos. Según Ching (2010), la plataforma de cada piso se apoya en las traviesas superiores del piso inferior. O'Brien (2010) adiciona que un woodframe mixto integra detalles de los estilos globo y plataforma, por ejemplo, el montaje integral del marco utilizando las piezas cortas. El woodframe mixto puede presentar áreas mojadas en albañilería de ladrillos. Un woodframe modular consiste en la variación moderna del modelo plataforma con elevados niveles de prefabricación. Sus paneles de pared son industrialmente producidos bi o tridimensionalmente, de modo semiacabado o acabado, dejando solamente la instalación en la zona de obras. Thallon (2008) apunta que los módulos son compactos.

Una casa modular en CLT se refiere a la vivienda producida modularmente mediante el empleo de paneles de madera contralaminada (cross laminated timber - CLT), los cuales componen integralmente cada sección bidimensional de cada pared, las cuales poseen carácter estructural. Crespell y Gaston (2011) indicaron que una construcción en CLT compite favorablemente con edificios de acero y concreto, complementando el uso de los entramados ligeros y pesados en madera. Mills (2010) cita que el CLT puede ser levantado rápidamente, reduciendo el tiempo de montaje y la mano de obra en el sitio de la construcción. Suárez-Riestra, Estévez-Cimadevila y Otero-Chans (2017) señalan que los sistemas modulares en CLT todavía permiten conexiones entre los paneles con vigas estructurales, como la madera laminada.

Las casas modulares para zonas de obras se fabrican con una técnica más simplificada en madera, cuya composición de pared envuelve un marco estructural compacto y liviano revestido por paneles de madera estructurales (compensado o tablero de virutas orientadas). La estandarización en módulos permite la producción seriada a gran escala y bajo costo.

Las casas móviles o unidades modulares móviles son casas transportables fabricadas en módulos (De Araujo et al., 2016b), las cuales se derivan de los remolques, específicamente de aquellos de grandes dimensiones con la finalidad de vivienda permanente para cualquier terreno o ambiente (Gutiérrez, 2008). Esta es una concepción de viviendas producidas bajo un rígido y robusto chasis de madera, cuya finalidad es servir de base y sustento, el cual presenta paredes aseguradas alrededor. Cada pared es unida entre sí y al chasis por tornillos reforzados para impedir el desencaje aun en situaciones de movimiento.

Ante las indicaciones propuestas en la literatura, este estudio tuvo como objetivo analizar la representatividad y la disponibilidad local de las técnicas habitacionales de madera en su respectivo sector productivo en Brasil, señalando el porcentaje de cada sistema constructivo, según el monto de empresas evaluadas con la intención de verificar las técnicas con mayor oferta en el país.

\section{Metodología}

Este estudio abarca un diagnóstico sectorial basado en dos tecnologías, para evaluar la oferta de las técnicas constructivas de viviendas en madera según la cantidad de sus empresas productoras en Brasil: encuestas por entrevistas presenciales realizadas aleatoriamente con sus propietarios, y búsqueda en sus sitios web. Se obtuvieron dos escenarios de muestreo poblacional de los productores de casas de madera, los cuales fueron analizados durante el año de 2015. Por medio de estas búsquedas en sitios web fue posible recoger datos referentes a las técnicas disponibles, que sirvieron como comparativo para los resultados de las entrevistas.

En las dos metodologías -búsqueda en sitios web y entrevistas personales-, se analizó la siguiente cuestión: ¿cuáles técnicas de vivienda en madera son ofrecidas comercialmente en cada empresa evaluada? Por la búsqueda en sitios web de las empresas estudiadas, los resultados fueron compilados conforme a la disponibilidad de esta información en tales plataformas. A su vez, las entrevistas personales siguieron el estándar de De Araujo et al. (2018), por la aplicación de un formulario semiestructurado con esta pregunta destinada a los empresarios.

Con base en la clasificación de casas de madera de De Araujo et al. (2016b), quince opciones de técnicas fueron indicadas a los empresarios: palillero con albañilería, entramado pesado por pilar-viga, casa móvil, casa de tabla y tapajuntas, casa modular para zona de obras, casa modular en CLT, woodframe modular, casa de estructura mixta en madera y albañilería, casa de tablas verticales clavadas, casa de tablas horizontales clavadas, casa de tablas horizontales entre pilares, woodframe mixto, woodframe plataforma, woodframe globo y casa de troncos.

La mayor parte de estas técnicas de carácter habitacional está disponible en todo el mundo, por ejemplo, las variedades del woodframe, las casas de tronco, viviendas modulares en CLT, entramados pesados por pilar-viga, y las casas de tablas horizontales entre pilares. Sin embargo, el palillero con albañilería es una técnica básicamente producida en el Brasil, sin registros de su presencia en otros países. En cuanto a los estratos sociales, la mayor parte de estos ejemplos puede servir desde opciones populares hasta altos estándares, a pesar del enfoque más popular de las viviendas de tabla y tapajuntas, y de las casas modulares para zona de obras, las cuales son ejemplos inferiores en calidad, precio y acabado.

Las respuestas tienen un enfoque cualitativo de selección múltiple con múltiples alternativas. 
La amplitud de la pregunta permite la inserción de nuevas técnicas, si fuera necesario. Después de obtenidos los datos, las márgenes de error para los dos métodos fueron dimensionados en software online de muestra estadística Raosoft Sample Size Calculator (2004), el cual prescribe un grado de confianza de $95 \%$ y una distribución de respuesta de $50 \%$, los cuales fueron respetados en la realización del cálculo.

\section{Resultados y discusión}

\section{Estructura actual del sector productivo de habitación en madera, en Brasil}

La población total de 210 productores de viviendas en madera situadas en Brasil fue calculada por las búsquedas en los sitios web, debido a la falta de datos sectoriales y de organizaciones o asociaciones para este sector. En relación con la localización y el alcance de la población evaluada para cada método, y las cantidades caracterizadas, la tabla 1 apunta la prospección de 210 empresas estimadas para todo el sector y las muestras de 207 empresas evaluadas por las búsquedas en los sitios web y 107 empresas evaluadas por las entrevistas.

Las búsquedas en los sitios web recogieron datos de $98,57 \%$ de toda la población estimada de productores de casas de madera, mientras que las entrevistas personales alcanzaron 50,95\%

\begin{tabular}{|c|c|c|c|}
\hline \multirow{2}{*}{ Estado brasileño } & \multicolumn{3}{|c|}{ Cantidad de productores } \\
\hline & Estimación total & Muestreo búsqueda & Muestreo entrevistas \\
\hline Amazonas & 1 & 1 & - \\
\hline Ceará & 1 & 1 & - \\
\hline Distrito Federal & 2 & 2 & 1 \\
\hline Espírito Santo & 4 & 4 & - \\
\hline Minas Gerais & 13 & 12 & 6 \\
\hline Paraná & 29 & 29 & 17 \\
\hline Rio de Janeiro & 8 & 7 & - \\
\hline Rio Grande do Sul & 49 & 48 & 19 \\
\hline Rondônia & 2 & 2 & - \\
\hline Santa Catarina & 64 & 64 & 32 \\
\hline São Paulo & 37 & 37 & 32 \\
\hline Otros estados & - & - & - \\
\hline Total & 210 & 207 & 107 \\
\hline
\end{tabular}

del mismo total. La dificultad de desplazamiento, debido a la amplia extensión del territorio brasileño, significó altos gastos financieros y de tiempo para el método de entrevistas personales, lo que limitó sensiblemente el muestreo, a pesar de su mayor posibilidad de recolección de datos y detalles junto a las empresas evaluadas personalmente.

La búsqueda en los sitios web permitió identificar que la mayoría empresarial de este sector se encuentra en los estados de las regiones sur y sureste. Por este método también fue verificado que 91,42 \% de la población total de 210 empresas rastreadas se refería a los productores situados en los tres estados de la región Sur: Santa Catarina, Rio Grande do Sul y Paraná, y dos de la región sureste: São Paulo y Minas Gerais (tabla 1). Así, la concentración de las empresas en esta amplia región contribuyó a optimizar la toma de los datos en las entrevistas in situ en un área de prospección menor y más viable.

La Tabla 2 indica la población observada y las muestras para los dos métodos de recolección de datos considerados, presentados en la tabla 1, entrevistas personales y búsquedas en sitios web, así como sus márgenes de error.

En ambas metodologías los márgenes de error fueron relativamente bajos, situándose, de acuerdo con las prescripciones de Pinheiro, Castro, Silva y Nunes (2011), muy por debajo del nivel aceptable de $10 \%$, cerca del nivel ideal de $5 \%$ en las entrevistas personales, y muy por debajo de ese punto en las búsquedas en sitios web. $\rightarrow$ Tabla 1. Cantidad de los productores de viviendas de madera en Brasil

Fuente: elaboración propia, 2018.
Resultados

Valores (unidades)

Margen de error (\%)

Tabla 2. Población, muestras y márgenes de error de la investigación Fuente: elaboración propia, 2017.

\begin{tabular}{|c|c|c|}
\hline Tamaño estimado de la población & 210 & - \\
\hline Cantidad muestral de las entrevistas personales & 107 & 6,65 \\
\hline Cantidad muestral de las búsquedas en sitios web & 207 & 0,82 \\
\hline
\end{tabular}




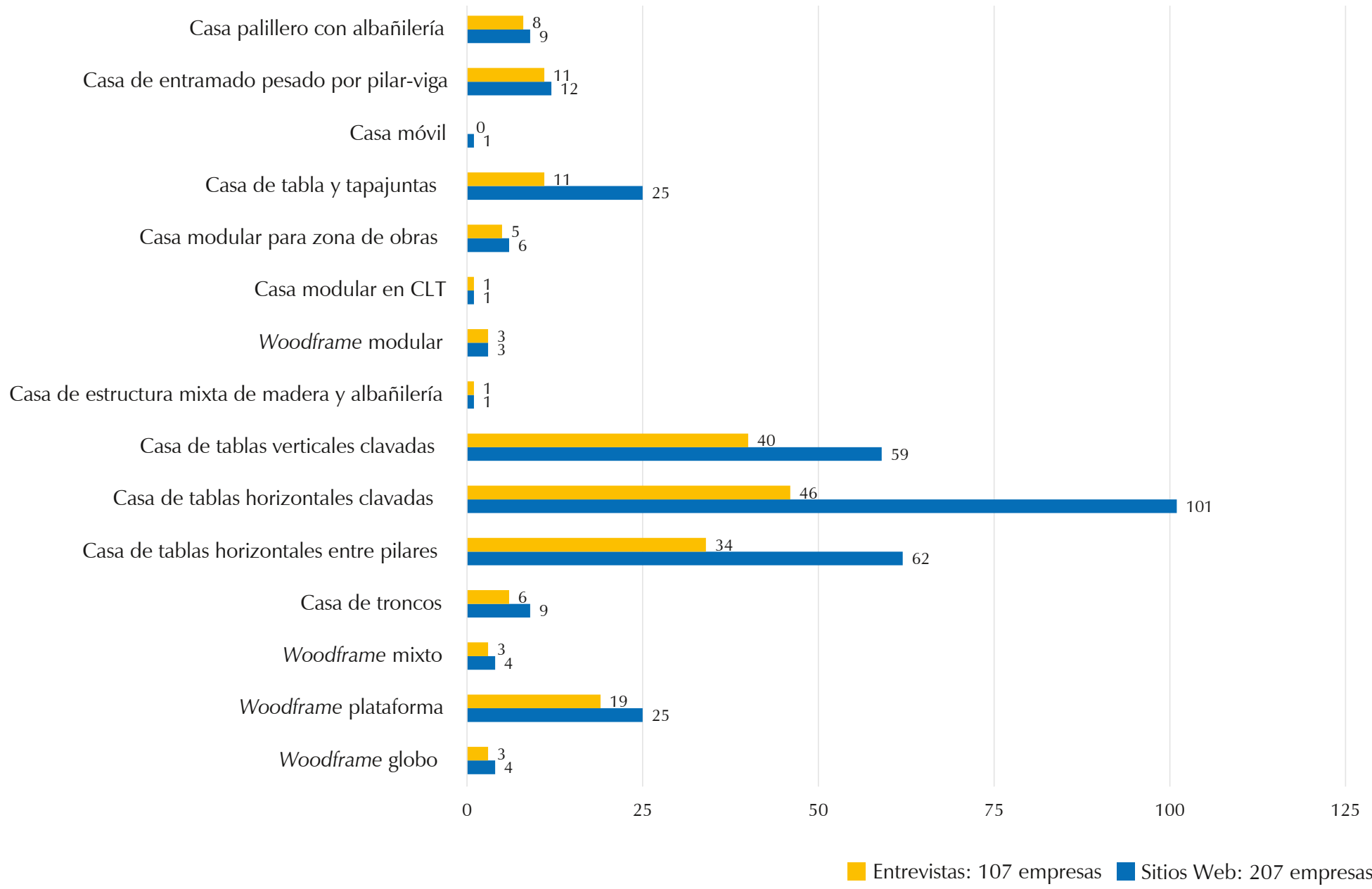

\section{Disponibilidad de las técnicas constructivas habitacionales en madera, en Brasil}

En ambas metodologías, los datos de la Figura 1 indicaron que un mismo productor de viviendas en madera puede producir una o más técnicas diferentes, independientemente de su concepto arquitectónico o su origen cronológico. Esta opción de disponibilidad de una o más técnicas, por parte de los productores, fue solamente una decisión empresarial o un deseo por una mayor línea de productos.

Los 107 productores de la muestra analizada en la metodología de entrevistas personales también fueron evaluados por el método de búsqueda en sitios web, a fin de verificar que todas las respuestas obtenidas fueran idénticas en lo relacionado con las preguntas sobre las técnicas constructivas en madera disponibles por las mismas. Esta condición de similitud de respuestas aseguró la credibilidad de las respuestas de los entrevistados.

La casa de tablas horizontales clavadas fue la técnica constructiva con mayor oferta de disponibilidad tipológica en las dos poblaciones observadas, la cual alcanzó un 48,79\% (101 empresas productoras) en la búsqueda en sitios web, y 42,99\% (46 empresas) en las entrevistas personales. En la metodología de búsqueda en los sitios web, el margen de error puede aumentar o reducir este valor en $0,41 \%$, en tanto que en las entrevistas personales el valor obtenido puede oscilar en $\pm 3,325 \%$ (Figura 1).
La segunda técnica con mayor oferta en los sitios web de las empresas brasileras fue la de las casas de tablas horizontales entre pilares, alcanzando $29,95 \%$ de toda la población analizada. En este método, la tercera técnica con mayor popularidad fue la de casas de tablas verticales clavadas, con un porcentaje de $28,50 \%$ ( $\pm 0,41 \%$ ). Sin embargo, este orden fue invertido para las entrevistas personales, ya que $37,38 \%$ de los productores ofrecen casas de tablas verticales clavadas y $31,78 \%$ ofrecen casas de tablas horizontales entre pilares. El margen de error de $\pm 3,325 \%$ para las entrevistas personales puede invertir tal posición, debido a la proximidad porcentual (Figura 1).

Los altos niveles de popularidad en las empresas evaluadas de estos tres ejemplos habitacionales fueron debidos a una mayor simplicidad conceptual de estas técnicas, tanto en términos productivos como en el uso de aserrados fácilmente disponibles en los proveedores de madera locales.

En las entrevistas personales, ninguna empresa productora de la técnica constructiva de casa móvil fue evaluada (Figura 1), en contraste con la verificación de una empresa productora de esa técnica para las búsquedas en sitios web.

También fue posible constatar que muchas de las empresas evaluadas todavía producen edificaciones en madera basadas o inspiradas en estilos europeos, como por ejemplo, la casa de tabla y tapajuntas, cuya popularidad era bastante alta en los siglos XIX y XX, según Imaguire Junior e Imaguire (2011).
A Figura 1. Cantidad de productores de casas de madera de acuerdo con la técnica

Fuente: elaboración propia, 2017. 
Un comparativo de los resultados obtenidos entre los métodos utilizados permitió verificar que $98,57 \%$ de las empresas fueron diagnosticadas en la búsqueda por internet en los sitios web corporativos, mientras que $50,95 \%$ fueron evaluadas en las entrevistas in situ, revelando un alcance muy satisfactorio en ambos casos (tabla 1).

Comparando con el estudio de Punhagui (2014), a pesar de que el foco era distinto, esta autora subrayó que "cuatro sistemas constructivos prefabricados en madera se hacen presentes en Brasil [...] casas de macho hembra, tapajuntas, troncos y entramado ligero". Las cuatro variedades de woodframe denotadas en este estudio fueron consideradas como una técnica única por Punhagui (2014): el entramado ligero en madera; eso podría generar distorsiones en el entendimiento de este sector productivo, dado que se presentan diferencias conceptuales y productivas; dichas diferencias fueron dilucidadas en la revisión bibliográfica de este trabajo. Otros cinco sistemas constructivos prefabricados en madera o derivados (entramado pesado, casa de tablas clavadas horizontales, verticales, casa modular para zonas de obras y casa modular en CLT), disponibles en el país (Figura 1) no fueron citados en aquel estudio.

Además, a pesar del concepto mixto con otros materiales, el palillo con albañilería y la casa de estructura mixta en madera y albañilería también permiten la prefabricación plena o parcial de sus componentes estructurales en madera; estos tampoco fueron considerados por Punhagui. Lo expuesto refuerza la necesidad de la difusión y la utilización de la clasificación de estos sistemas constructivos de madera propuesto por De Araujo et al. (2016b), así como la realización de más investigaciones como la elaborada en este estudio, buscando detallar todo el sector productivo de casas de madera, no solo bajo la óptica de la prefabricación industrial, sino también de las empresas artesanales y semiindustriales.

Por medio de las clasificaciones de las técnicas constructivas habitacionales de Mello (2007) y de De Araujo et al. (2016b), fue posible ordenar las técnicas disponibles en las empresas de la muestra (Figura 1) en tradicionales y en contemporáneas, conforme a la literatura aquí expuesta, as como cuantificar la presencia porcentual de esas dos posibilidades cronológicas en los productores brasileños de casas de madera (Figura 2).
Los dos métodos evaluados (entrevistas personales y búsquedas en sitios web) identificaron, de manera similar, que las técnicas contemporáneas, es decir, las tecnologías modernas, están disponibles en la mayoría de las empresas existentes en Brasil (Figura 2). A partir de una pequeña diferencia entre los valores obtenidos, estos dos métodos detectaron que casi todos los productores ofrecen técnicas contemporáneas, aunque una parte menor, pero considerable, de esas empresas todavía produce técnicas tradicionales basadas en conceptos más antiguos. Este resultado tiene fuerte relación con la búsqueda por productos más modernos por parte del público, y con la producción de técnicas constructivas basadas en materias primas de mayor disponibilidad en todo el Brasil.

Para ambas metodologías, cerca del $8 \%$ de las empresas ofrecen simultáneamente las técnicas constructivas tradicionales y las contemporáneas.

\section{Conclusiones}

Las características sectoriales obtenidas han expuesto una muestra muy diversificada y consistente para las dos metodologías, a pesar de sus distintas características para la recolección de datos. Pese al mayor público evaluado por el método de búsqueda en sitios web, los dos métodos utilizados en la recolección de datos presentaron resultados similares. Por medio de esta comparación de los dos métodos se pudo identificar que ambas soluciones son viables y posibles para la recolección de datos a fin de caracterizar cualquier sector productivo. Para este estudio, la búsqueda en sitios web presenta mayor restricción en la cantidad disponible de información, pero fue más viable por cuenta de los mayores costos de desplazamiento que implica la metodología de entrevistas personales, la cual permite una mayor recolección de datos junto al entrevistado.

El orden de disponibilidad fue similar en los dos métodos para casi todas las técnicas constructivas. Las cuatro técnicas en madera con mayores índices de disponibilidad para comercialización en las empresas fueron, en su orden, las casas de tablas horizontales clavadas, las casas de tablas horizontales entre pilares, las de tablas verticales clavadas, y los woodframes tipo plataforma.

Esta caracterización permitió, además, considerar que el sector brasileño de casas de madera
Técnicas contemporáneas

Técnicas tradicionales

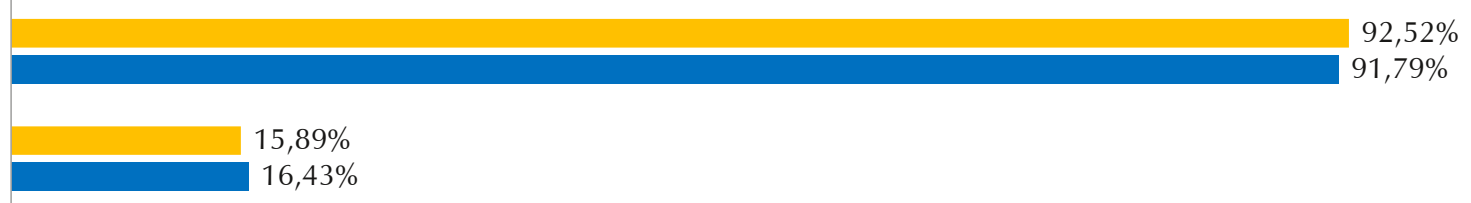


se está enfocando en la oferta de tipologías arquitectónicas contemporáneas, lo que refuerza una disponibilidad de soluciones constructivas más eficientes y actualizadas, las cuales emplean materias primas de mayor valor agregado, tales como la madera maciza aserrada estandarizada y los derivados compuestos de madera.
Finalmente, se verificó que el sector estudiado cuenta con pocas empresas consolidadas en funcionamiento, en virtud de no mostrar una representación más notable y presente en todos los estados brasileños, tal como ocurre con las casas de albañilería que actualmente muestran mayor visibilidad de mercado en Brasil.

\section{Referencias}

Benoit, Y. y Paradis, T. (2008). Construction de maisons à ossature bois. Saint-Germain: Eyrolles.

Calil Júnior, C. y Dias, A. A. (1997). Utilização da madeira em construções rurais. Revista brasileira de engenharia agrícola e ambiental, 1 (1), 71-77. doi: http://dx.doi.org/10.1590/18071929/agriambi.v1n1p71-77

Casema (1998). Manual de Montagem. Bom Jesus dos Perdões: Casema.

César, S. F. (2002). Chapas de madeira para vedação vertical de edificações produzidas industrialmente: projeto conceitual (tesis doctoral inédita). Universidade Federal de Santa Catarina, Brasil. Recuperado de: https://repositorio.ufsc.br/handle/123456789/83182

Charles, F. W. B. y Charles M. (1984). Conservation of timber buildings. London: Hutchinson $\&$ Co.

Ching, F. (2010). Técnicas de construção ilustradas. Porto Alegre: Brookman.

Crespell, P. y Gaston, C. (2011). The value proposition for cross-laminated timber. Québec: FPInnovations.

De Araujo, V. A., Cortez-Barbosa, J., Garcia, J. N. Gava, M., Laroca, C. y César, S. F. (2016a). Woodframe: light framing houses for developing countries. Revista de la construcción, 15(2), 78-87. doi: http://dx.doi.org/10.4067/ S0718-915X2016000200008

De Araujo, V. A., Cortez-Barbosa, J., Gava, M., Garcia, J. N., Souza, A. J. D., Savi, A. F., Morales, E. A. M., Molina, J. C., Vasconcelos, J. S., Christoforo, A. L. y Lahr, F. A. R. (2016b). Classification of wooden housing building systems. BioResources, 11(3), 7889-7901. doi: http://dx.doi.org/10.15376/biores.11.3.De Araujo

De Araujo, V. A., Vasconcelos, J. S., Cortez-Barbosa, J., Gava, M., Alves, P. R. G., Vasconcelos, J. C. S., Gonçalves, M. T. T. y Garcia, J. N. (2015). Maquinário na indústria de casas de madeira do Estado do Paraná. V Congresso Florestal Paranaense (Curitiba, 06-09 de Octubre de 2015). Curitiba: APRE, 1-7.

De Araujo, V. A., Gava, M., Vasconcelos, J. S., Morales, E. A. M., Alves, P. R. G., Cortez-Barbosa, J., Gonçalves, M. T. T. y Garcia, J. N. (2016c). Machinery of wooden housing industry in the Brazilian State of São Paulo. XIV World Conference on Timber Engineering (Viena, 22-25 de agosto de 2016). Viena: WCTE, 1-8.

De Araujo, V. A., Vasconcelos, J. S., Cortez-Barbosa, J., Morales, E. A. M., Gava, M., Savi, A. F. y Garcia, J. N. (2016d). Wooden residential buildings - a sustainable approach. Bulletin of the Transilvania University of Brasov Series II: Forestry - Wood Industry - Agricultural Food Engineering, 9(2), 53-62. Recuperado de: http://webbut.unitbv.ro/bulletin/Series\%20I/ BULETIN\%20I/08_\%20De\%20Araujo.pd

De Araujo, V. A., Vasconcelos, J. S., Morales, E. A. M., Savi, A. F., Hindman, D. P., O'Brien, M. J., Negrão, J. H. J. O., Christoforo, A. L., Lahr, F.
A. R., Cortez-Barbosa, J., Gava, M. y Garcia, J. N. (2018). Difficulties of wooden housing production sector in Brazil. Wood Material Science \& Engineering, 1-10. doi: http://dx. doi.org/10.1080/17480272.2018.1484513

Gutiérrez, R. M. (2008). Casas móveis: experiência na Região Oeste do Paraná (tesis de maestría). Universidade de São Paulo, Brasil. Recuperado de: www.teses.usp.br/teses/disponiveis/16/16134/tde-16042010-095254/ en.php

Imaguire Junior, K. y Imaguire, M. R. G. (2011). A casa de araucária (vol. 1). Curitiba: Instituto Arquibrasil.

Kniffen, F. y Glassie, H. (1966). Building in wood in the Eastern United States. Geographical Review, 56(1), 40-66. doi: http://dx.doi. org/10.2307/212734

Kretschmann, D. E. (2010). Commercial lumber, round timbers, and ties. En: Forest Products Laboratory. Wood handbook - wood as an engineering material (centennial edition, pp. 1-25). Madison, WI: Department of Agriculture, Forest Service, Forest Products Laboratory. Recuperado de: https://www.fpl.fs.fed. us/documnts/fplgtr/fpl gtr190.pdf

Lessa, E. M. M. y Silva, R. D. (2003). Desenvolvimento de sistema construtivo para habitação rural em madeira de reflorestamento. Akrópolis, 11(3), 180-183. doi: https://doi. org/10.25110/akrópolis.v11i3.371

Martínez-Osorio, P., Barana, M., Rocha-Carneiro, R. y Paschoarelli, L. (2017). Innovación, design y sostenibilidad social: nuevas tendencias para el desarrollo local en la ciudad contemporánea. Revista de Arquitectura, 19(2), 68-77. doi: http://dx.doi.org/10.14718/RevArq.2017. 19.2.1406

Mello, R. L. (2007). Projetar em madeira: uma nova abordagem (tesis de maestría). Universidade de Brasília, Brasil. Recuperado de: http://repositorio.unb.br/handle/10482/3133

Mills, F. (2010). Cross laminated timber frames. Letchworth: Willmott Dixon.

Morgado, L., Guedes, M. C., Ferreira, J. G. y Cruz, H. (2012). Classificação de sistemas de construção em madeira para habitação. IV Congresso Nacional da Construção (Coimbra, 19-20 de diciembre de 2012). Coimbra: Universidade de Coimbra, 1-12. Recuperado de: https://www.academia.edu/7287840/ CLASSIFICA \%C3\%87\%C3\%83O DE SISTEMAS DE CONSTRU \%C3 \%87\%C $3 \%$ 83O_EM_MĀDEIRA_PARA_HABITA $\%$ C $3 \%$ $87 \% \overline{\mathrm{C}} 3 \% \overline{8} 3 \mathrm{O}$

Neufert, P. y Neff, L. (2013). Casa • apartamento - jardim: projetar com conhecimento • construir corretamente. Barcelona: Gustavo Gili.

Novas-Cabrera, J. A. (2010). Sistemas constructivos prefabricados aplicables a la construcción de edificaciones en países en desarrollo (tesis de maestría). Universidad Politécnica de Madrid, España. Recuperado de: http:// oa.upm.es/4514/1/TESIS MASTER JOEL NOVAS CABRERA.pdf
O'Brien, M. J. (2010). Hybrids on the way to the western platform frame: two structures in Western Virginia. Preservation Education \& Research, 3, 37-52. Recuperado de: http://mjobrien.com/Papers/OBrien article hybrids_on_the_way_to_the_western_platform_frame.pdf

Pinheiro, R. M., Castro, G. C., Silva, H. H. y Nunes, J. M. G. (2011). Pesquisa de Mercado. Rio de Janeiro: FGV.

Presnitz, R. (2009). The art of timber framing. Natural Life Magazine, 23-25. Recuperado de: https://www.life.ca/naturallife/0908/The-Artof-Timber-Framing-NaturalLifeMagazine.pdf

Punhagui, K. R. G. (2014). Potencial de reducción de las emisiones de $\mathrm{CO}_{2}$ y de la energía incorporada en la construcción de viviendas en Brasil mediante el incremento del uso de la madera (tesis doctoral). Universitat Politecnica de Catalunya / Universidade de São Paulo, España / Brasil. Recuperado de: https:// upcommons.upc.edu/handle/2117/95469

Raosoft(2004).RaosoftSampleSizeCalculator.Recuperado de: http://www.raosoft.com/sample size.html

Shimbo, I. y Ino, A. (1997). A madeira de reflorestamento como alternativa sustentável para produção de habitação social. I Encontro Nacional sobre Edificações e Comunidades Sustentáveis (Canela, 18-21 de noviembre de 1997). Porto Alegre: ANTAC, 157-162.

Suárez-Riestra, F. Estévez-Cimadevila, J. y Otero-Chans, D. (2017). Metodología de análisis de forjados autotensados de madera. Informes de la Construcción, 69(547), 1-9. doi: https://dx.doi.org/10.3989/ic.16.076

Szücs, C. A. y Batista, F. D. (2007). A arquitetura de madeira na Região de Curitiba: estudo comparativo entre a casa tradicional e contemporânea. II Encontro Nacional sobre Edificações e Comunidades Sustentáveis (Campo Grande, 12-14 de noviembre de 2007). Porto Alegre: ANTAC, 798-807.

Thallon, R. (2008). Graphic guide to frame construction. Newtown: Taunton Press.

Tosolini, P. (2008). Other itineraries: Modern architects on countryside roads. The Journal of Architecture, 13(4), 427-451. doi: https:// dx.doi.org/10.1080/13602360802328107

Wacker, J. P. (2010). Use of wood in buldings and bridges. En: Forest Products Laboratory, Wood handbook - wood as an engineering material (centennial edition, pp. 1-13). Madison, WI: Department of Agriculture, Forest Service, F orest Products Laboratory. Recuperado de: https://www.fpl.fs.fed.us/documnts/ fplgtr/fpl_gtr190.pdf

Wagner, J. D. (2009). Ultimate guide to house framing: Plan, design, build. Upper Saddle River: Creative Homeowner.

Weimer, G. (2005). Arquitetura popular da imigração alemã. Porto Alegre: Editora da UFRGS.

Zani, A. C. (2013). Arquitetura em madeira. Londrina: Eduel. 


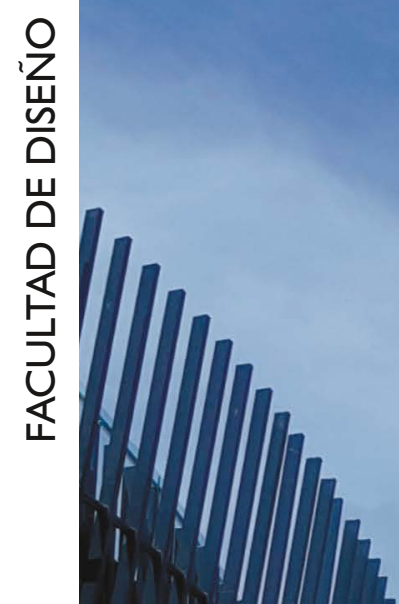

Vol.

\section{Nro. 1REVISTA DE ARQUITECTURA}
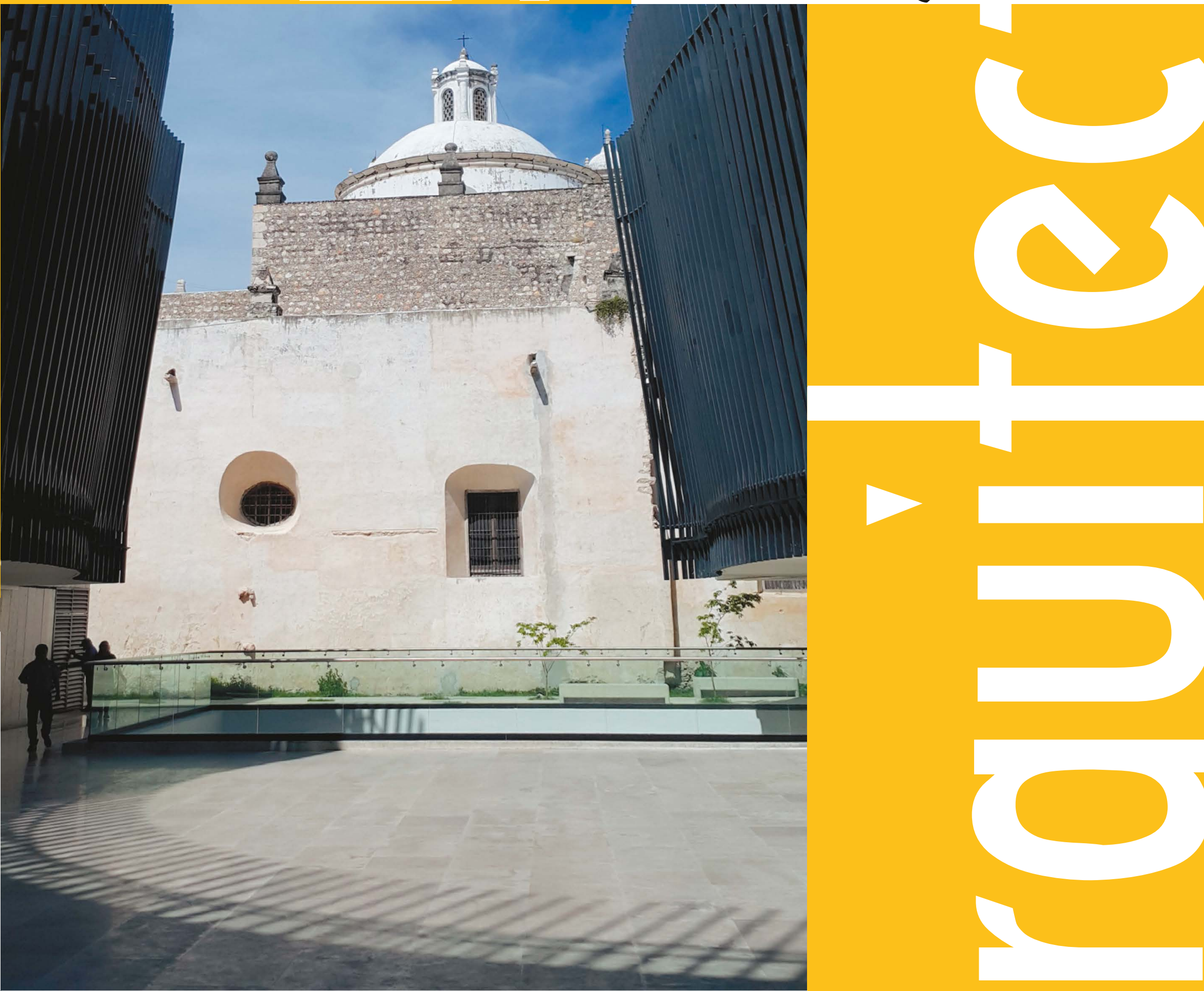
A) Portada: Palacio de la Música y Rectoria El J Júśs Tercera Orden. Mérida, Yucatán (México).

Fotografía: César Eligio-Triana (2018, septiembre) CC BY-NC

\section{(c) (1) ( $)$}

A Orientación editorial

\section{Enfoque y alcance}

La Revista de Arquitectura (Bogotá) ( (ISSN 1657-0308 Impresa y E-ISSN 2357-626X en línea) es una publicación seriada de acceso abierto, arbitrada mediante revisión por pares (doble ciego) e indexada, en donde se publican resultados de investigación originales e inéditos.

Está dirigida a la comunidad académica y profesional de las áreas afines a la disciplina. Es editada por la Facultad de Diseño y el Centro de Investigaciones (CIFAR) de la Universidad Católica de Colombia en Bogotá (Colombia).

La principal área científica a la que se adscribe la Revista de Arquitectura (Bogotá) según la OCDE es:

Gran área: 6. Humanidades

Área: 6.D. Arte

\section{Disciplina: 6D07. Arquitectura y Urbanismo}

También se publican artículos de las disciplinas como 2A02, Ingeniería arquitectónica; 5G03, Estudios urbanos (planificación y desarrollo); 6D07, Diseño.

Los objetivos de la Revista de Arquitectura (Bogotá) son:

- Promover la divulgación y difusión del conocimiento generado a nivel local, nacional e internacional

- Conformar un espacio para la construcción de comunidades académicas y la discusión en torno a las secciones definidas.

- Fomentar la diversidad institucional y geográfica de los autores que participan en la publicación.

- Potenciar la discusión de experiencias e intercambios científicos entre investigadores y profesionales.

- Contribuir a la visión integral de la arquitectura, por medio de la concurrencia y articulación de las secciones mediante la publicación de artículos de calidad.

- Publicar artículos originales e inéditos que han pasado por revisión de pares, para asegurar que se cumplen las normas éticas, de calidad, validez científica, editorial e investigativa.

- Fomentar la divulgación de las investigaciones y actividades desarrolladas en la Universidad Católica de Colombia.
Palabras clave de la Revista de Arquitectura (Bogotá): arquitectura, diseño, educación arquitectónica, proyecto y construcción, urbanismo.

Idiomas de publicación: español, inglés, portugués y francés. Título abreviado: Rev. Arquit.

\section{Titulo corto: RevArq}

\section{Políticas de sección}

La revista se estructura en tres secciones correspondientes a las líneas de investigación activas y aprobadas por la institución, y dos complementarias, que presentan dinámicas propias de la Facultad de Diseño y las publicaciones relacionadas con la disciplina.

Cultura y espacio urbano. En esta sección se publican los artículos que se refieren a fenómenos sociales en relación con el espacio urbano, atendiendo aspectos de la historia, el patrimonio cultural y físico, y la estructura formal de las ciudades y el territorio.

Proyecto arquitectónico y urbano. En esta sección se presentan artículos sobre el concepto de proyecto, entendido como elemento que define y orienta las condiciones proyectuales que devienen en los hechos arquitectónicos o urbanos, y la forma como estos se convierten en un proceso de investigación y nuevo de conocimiento. También se presentan proyectos que sean resultados de investigación, los cuales se validan por medio de la ejecución y transformación en obra construida del proceso investigativo. También se contempla la publicación de investigaciones relacionadas con la pedagogía y didáctica de la arquitectura, el urbanismo y el diseño.

Tecnología, medioambiente y sostenibilidad. En esta sección se presentan artículos acerca de sistemas estructurales, materiales y procesos constructivos, medioambiente y gestión, relacionados con los entornos social-cultural, ecológico y económico.

Desde la Facultad. En esta sección se publican artículos generados en la Facultad de Diseño, relacionados con las actividades de docencia, extensión, formación en investigación o internacionalización, las cuales son reflejo de la dinámica y de las actividades realizadas por docentes, estudiantes y egresados; esta sección no puede superar el $20 \%$ del contenido.

Textos. En esta sección se publican reseñas, traducciones y memorias de eventos relacionados con las publicaciones en Arquitectura y Urbanismo.

\section{A Frecuencia de publicación}

Desde 1999 y hasta el 2015, la Revista de Arquitectura (Bogotá) publicó un volumen al año, a partir del 2016 se publicarán dos números por año en periodo anticipado, enero-junio y julio-diciembre, pero también maneja la publicación anticipada en línea de los artículos aceptados (versión Post-print del autor).

La Revista de Arquitectura (Bogotá) se divulga mediante versiones digitales (PDF, HTML, EPUB, XML) e impresascon un tiraje de 700 ejemplares, los tiempos de producción de estas versiones dependerán de los cronogramas establecidos por la editorial.

Los tiempos de recepción-revisión-aceptación pueden tardar entre seis y doce meses dependiendo del flujo editorial de cada sección y del proceso de revisión y edición adelantado.

Con el usuario y contraseña asignados, los autores pueden ingresar a la plataforma de gestión editorial y verificar el estado de revisión, edición o publicación del artículo.
A Canje

La Revista de Arquitectura (Bogotá) está interesada en establecer canje con publicaciones académicas, profesionales o científicas del área de Arquitectura y Urbanismo, como medio de reconocimiento y discusión de la producción científica en el campo de acción de la publicación.

\section{Mecanismo}

Para establecer canje por favor descargar, diligenciar y enviar el formato: RevArq FP20 Canjes

\section{Universidad Católica de Colombia (2019, enero-junio). Revista de Arquitectura (Bogotá), $2 I(\mathrm{I})$ I-120. Doi: 10.14718 \\ ISSN: 1657-0308 E-ISSN: 2357-626X \\ Especificaciones: Formato: $34 \times 24 \mathrm{~cm}$ Papel: Mate $115 \mathrm{~g}$ Tintas: Negro y policromía}

A Contacto

Dirección postal:

Avenida Caracas No. 46-72.

Universidad Católica de Colombia

Bogotá D.C.(Colombia)

Código postal: 111311

Facultad de Diseño

Centro de Investigaciones (CIFAR).

Sede El Claustro. Bloque "L", 4 piso

Diag. 46a No. $15 b-10$

Editor, Arq. César Eligio-Triana

Teléfonos:

+57 (1) $3277300-3277333$

Ext. $3109 ; 3112$ o 5146

Fax: +57 (1) 2858895
Correo electrónico:

revistadearquitectura@ucatolica.edu.co

cifar@ucatolica.edu.co

Página WEB:

www.ucatolica edu.co

vínculo Revistas científicas

http://publicaciones.ucatolica.edu.co revistas-cientificas

http://editorial.ucatolica.edu.co/ojsucatolica/revistas_ucatolica/index.php/RevArq 
Universidad Católica de Colombia

Presidente

Édgar Gómez Betancourt

Vicepresidente - Rector

Francisco José Gómez Ortiz

Vicerrector Jurídico

Edwin de Jesús Horta Vásquez

Vicerrector Administrativo

Édgar Gómez Ortiz

Vicerrector Académico

Elvers Medellín Lozano

Vicerrector de Talento Humano

Ricardo López Blum

Director de Investigaciones

Edwin Daniel Durán Gaviria

Directora Editorial

Stella Valbuena García

\section{Facultad de Diseño}

Decano

Werner Gómez Benítez

Director de docencia

Jorge Gutiérrez Martínez

Directora de extensión

Mayerly Rosa Villar Lozano

Director de investigación

Hernando Verdugo Reyes

Director de gestión de calidad

Augusto Forero La Rotta

Comité asesor externo

Facultad de Diseño

Édgar Camacho Camacho

Martha Luz Salcedo Barrera

Samuel Ricardo Vélez
Facultad de Diseño

Centro de Investigaciones - CIFAR

\section{REVISTA DE ARQUITECTURA \\ Revista de Arquitectura \\ (Bogotá)}

Revista de acceso abierto,

arbitrada e indexada

Publindex: Categoría B. Índice Bibliográfico Nacional IBN.

Esci: Emerging Source Citation Index.

Doaj: Directory of Open Access Journals.

Redalyc: Red de Revistas Cientificas de América Latina y el Caribe,

España y Portugal.

SciELO: Scientific Electronic Library Online - Colombia

Redib: Red Iberoamericana de Innovación y Conocimiento Cientifico.

Ebsco: EBSCOhost Research Databases.

Clase: Base de datos bibliográfica de revistas de ciencias sociales y

humanidades.

Latindex: Sistema Regional de Información en Línea para Revistas

Científicas de América Latina, el Caribe, España y Portugal (Directorio

y catálogo).

Dialnet: Fundación Dialnet - Biblioteca de la Universidad de La Rioja.

LatinRev: Red Latinoamericana de Revistas Académicas en Ciencias

Sociales $y$ Humanidades.

Proquest: ProQuest Research Library.

Miar: Matrix for the Analysis of Journals.

Sapiens Research: Ranking de las mejores revistas colombianas según

visibilidad internacional.

Actualidad Iberoamericana: (Índice de Revistas) Centro de Información

Tecnológica (CIT).

Google Scholar

Arla: Asociación de Revistas latinoamericanas de Arquitectura.

\section{Editorial}

Av. Caracas № 46-72, piso 5

Teléfono: 3277300 Ext. 5145

editorial@ucatolica.edu.co

www.ucatolica.edu.co

http://publicaciones.ucatolica.edu.co)

Impresión:

JaVEGRAF

Calle 46A No82-54 Int. 2

Bogotá, D. C., Colombia

http://www.javegraf.com.co/index.php

Enero de 2019
Director

Werner Gómez Benítez

Editor

César Eligio-Triana

Editores de sección

(1) Myriam Stella Díaz-Osorio

(1) Carolina Rodríguez-Ahumada

(4) Anna Maria Cereghino-Fedrigo

\section{Equipo editorial}

Coordinadora editorial

María Paula Godoy Casasbuenas

mpgodoy@ucatolica.edu.co

Diseño y montaje

Juanita Isaza

juanaisaza@gmail.com

Traductoras

Inglés

Erika Tanacs

etanacs25@gmail.com

Portugués

Roanita Dalpiaz

roanitad@gmail.com

Correctora de estilo

María José Díaz Granados M.

mariajose_dgm@yahoo.com.co

Página Web

Centro de investigaciones (CIFAR)

Distribución y canjes

Claudia Álvarez Duquino

calvarez@ucatolica.edu.co
Comité editorial y científico

Cultura y espacio urbano

Carlos Mario Yory, PhD

Universidad Católica de Colombia. Bogotá, Colombia

Sonia Berjman, $\mathrm{PhD}$

ICOMOS-IFLA, Buenos Aires, Argentina

Juan Carlos Pérgolis, MSc Universidad Piloto de Colombia. Bogotá, Colombia

Beatriz García Moreno, PhD

Universidad Nacional de Colombia. Bogotá, Colombia

Proyecto arquitectónico y urbano

Jean-Philippe Garric, PhD, HDR

Université Paris I Panthéon-Sorbonne. Paris, Francia

Debora Domingo Calabuig, PhD

Universidad Politécnica de Valencia, España

Dania González Couret, PhD

Universidad Tecnológica de La Habana, Cuba

Hugo Mondragón López, PhD Pontificia Universidad Católica de Chile. Santiago, Chile

Juan Pablo Duque Cañas, PhD

Universidad Nacional de Colombia. Bogotá, Colombia

Tecnología, medioambiente y sostenibilidad

Mariano Vázquez Espí, PhD

Universidad Politécnica de Madrid, España

Denise Helena Silva Duarte, PhD Universidade de São Paulo (USP), Brasil

Luis Carlos Herrera Sosa, PhD Universidad Autónoma de Ciudad Juárez, México

Claudio Varini, PhD

Universidad Católica de Colombia. Bogotá, Colombia

Luis Gabriel Gómez Azpeitia, PhD Universidad de Colima. Colima, México 


\section{CONTENIDO}
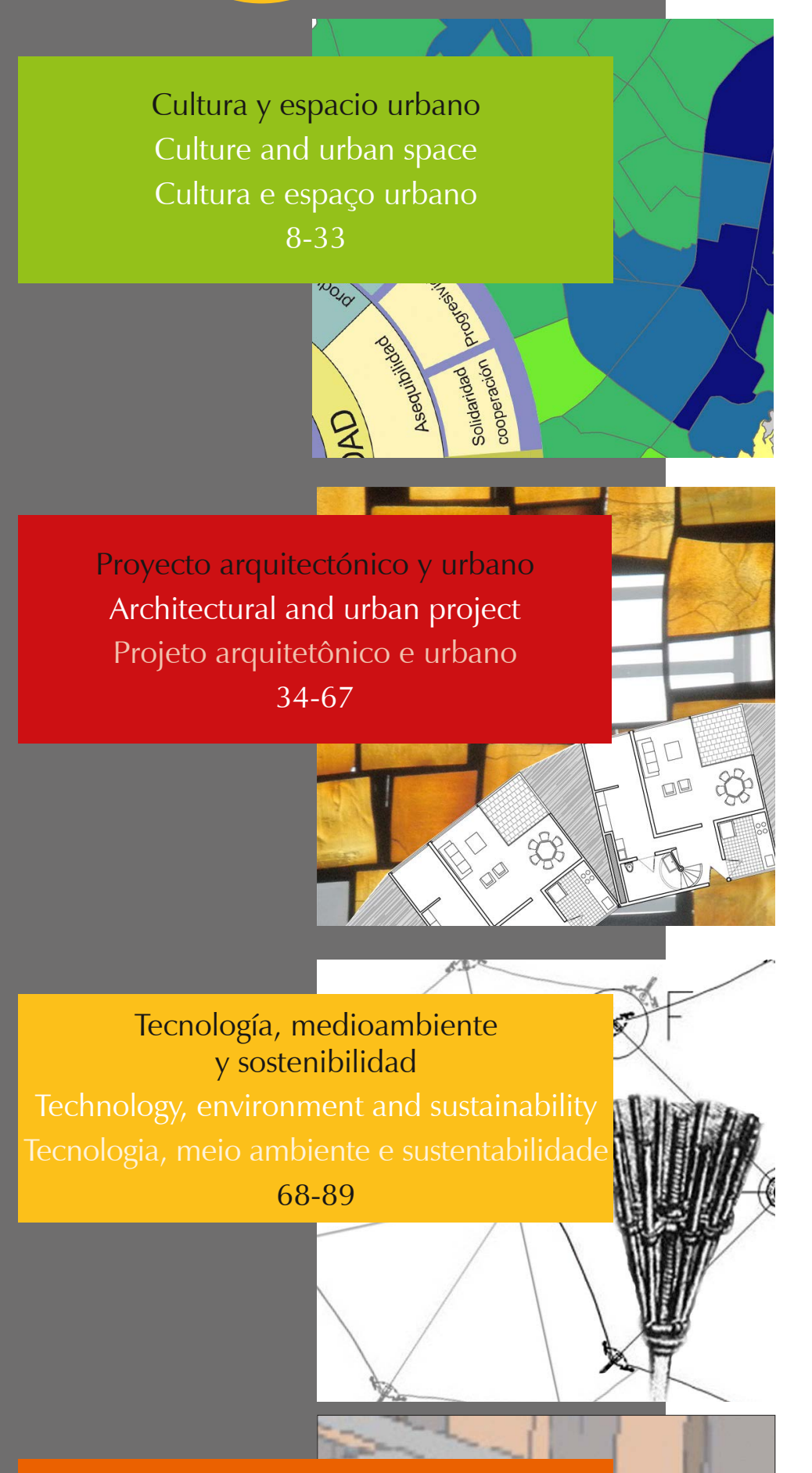

Desde la Facultad

From the Faculty

Da faculdade

90-109

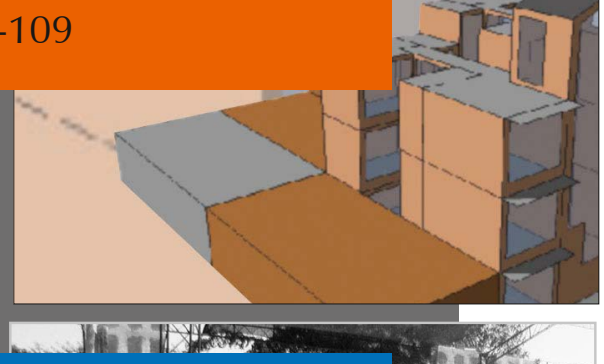

Textos

Texts

Textos

110-118
Revistas en tiempos tecno-humanos

Julio Arroyo

Pág. 3

ES

Índice de caminabilidad para la ciudad de Bogotá

Julián Alberto Gutiérrez-López
Yolanda Beatriz Caballero-Pérez
Rubén Alejandro Escamilla-Triana

ES

Pág. 8

Principios, criterios y propósitos de desarrollo sustentable para la redensificación en contextos urbanos informales
Juan José Castiblanco-Prieto
Fabián Adolfo Aguilera-Martínez
Fabián Alonso Sarmiento-Valdés

Pág. 21

ES

Complejidad y constructivismo en la nueva tradición de la arquitectura de la posguerra

Francisco Javier Fuentes-Farías

Pág. 34 ES

Conservación del arte contemporáneo

El caso de Mathias Goeritz en la Catedral

Metropolitana de México

Alberto Cedeño-Valdiviezo

Pablo Torres-Lima

Pág. 44

\section{ES EN}

Operando desde la forma: un procedimiento

para la valoración de la vivienda colectiva

Julián Camilo Valderrama-Vidal

Pág. 54

ES

Disponibilidad de las técnicas constructivas

de habitación en madera, en Brasil

Victor A. De Araujo

Carlos M. Gutiérrez-Aguilar

Juliana Cortez-Barbosa

Maristela Gava

José N. Garcia

Pág. 68

ES

Diseño y construcción de un paraguas plegable para espacios arquitectónicos

Carlos César Morales-Guzmán

Pág. 76

ES EN

Envolventes eficientes

Relación entre condiciones ambientales, espacios confortables

y simulaciones digitales

Natalia Medina-Patrón

Jonathan Escobar-Saiz

Pág. 90

ES

(Re)pensando el enfoque tecnológico:

el caso del Centro Experimental de la Vivienda

Económica (CEVE) en Argentina

Gustavo Pelegrin

Laila Fleker

Aurelio Ferrero

Pág.110 
La postulación de un artículo a la Revista de Arquitectura (Bogotá) indica que- el o los autores certifican que conocen y aceptan la política editorial, para lo cual firmarán en original y remitirán el formato RevArq FP00 Carta de originalidad.

La Revista de Arquitectura (Bogotá) maneja una política de Autoarchivo VERDE, según las directrices de SHERPA/RoMEO, por lo cual el autor puede:

- Pre-print del autor: Archivar la versión pre-print (la versión previa a la revisión por pares

- Post-print del autor: Archivar la versión post-print (la versión final posterior a la revisión por pares

- Versión de editor/PDF: Archivar la versión del editor - PDF/HTML/XLM en la maqueta de la Revista de Arquitectura (Bogotá).

El Autoarchivo se debe hacer respetando la licencia de acceso abierto, la integridad y la imagen de la Revista de Arquitectura (Bogotá), también se recomienda incluir la referencia, el vínculo electrónico y el DOI.

El autor o los autores son los titulares del Copyright (c) del texto publicado y la Editorial de la Revista de Arquitectura (Bogotá) solicita la firma de una autorización de reproducción del artículo (RevArq FP03 Autorización reproducción), la cual se acoge a la licencia CC, donde se expresa el derecho de primera publicación de la obra.

La Revista de Arquitectura (Bogotá) se guía por las normas internacionales sobre propiedad intelectual y derechos de autor, y de manera particular el artículo 58 de la Constitución Política de Colombia, la Ley 23 de 1982 y el Acuerdo 172 del 30 de septiembre de 2010 (Reglamento de propiedad intelectual de la Universidad Católica de Colombia)

Para efectos de autoría y coautoría de artículos se diferencian dos tipos: "obra en colaboración" y "obra colectiva". La primera es aquella cuya autoría corresponde a todos los participantes al ser fruto de su trabajo conjunto. En este caso, quien actúa como responsable y persona de contacto debe asegurar que quienes firman como autores han revisado y aprobado la versión final, y dan consentimiento para su divulgación. La obra colectiva es aquella en la que, aunque participan diversos colaboradores, hay un autor que toma la iniciativa la coordinación y realización de dicha obra. En estos casos, la autoría corresponderá a dicha persona (salvo pacto en contrario) y será suficiente únicamente con su autorización de divulgación.

El número de autores por artículo debe estar justificado por el tema, la complejidad y la extensión, y no deberá ser superior a la media de la disciplina, por lo cual se recomienda que no sea mayor de cinco. El orden en que se enuncien corresponderá a los aportes de cada uno a la construcción del texto, se debe evitar la autoría ficticia o regalada. Si se incluyen más personas que trabajaron en la investigación se sugiere que sea en calidad de colaboradores o como parte de los agradecimientos. La Revista de Arquitectura (Bogotá) respetará el número y el orden en que figuren en el original remitido. Si los autores consideran necesario, al final del artículo pueden incluir una breve descripción de los aportes individuales de cada uno de firmantes.

La comunicación se establece con uno de los autores, quien a su vez será el responsable de informar a los demás autores de las notificaciones emitidas por la Revista de Arquitectura (Bogotá).

En virtud de mantener el equilibro de las secciones y las mismas oportunidades para todos los participantes, un mismo autor puede postular dos o más artículos de manera simultánea; si la decisión editorial es favorable y los artículos son aceptados, su publicación se realizará en números diferentes.

\section{A Acceso abierto}

La Revista de Arquitectura (Bogotá), en su misión de divulgar la investigación y apoyar el conocimiento y la discusión en los campos de interés, proporciona acceso abierto, inmediato e irrestricto a su contenido de manera gratuita mediante la distribución de ejemplares impresos y digitales. Los interesados pueden leer, descargar, guardar, copiar y distribuir, imprimir, usar, buscar o referenciar el texto completo o parcial de los artículos o la totalidad de la Revista de Arquitectura (Bogotá).

\section{(c) (1) (3)}

Esta revista se acoge a la licencia Creative Commons (CC BY NC de Atribución - No comercial 4.0 Internacional): "Esta licencia permite a otros entremezclar, ajustar y construir a partir de su obra con fines no comerciales, y aunque en sus nuevas creaciones deban reconocerle su autoría y no puedan ser utilizadas de manera comercial, no tienen que estar bajo una licencia con los mismos términos".

La Revista de Arquitectura es divulgada en centros y grupos de investigación, en bibliotecas y universidades, y en las principales facultades de Arquitectura mediante acceso abierto a la versión digital y suscripción anual al ejemplar impreso o por medio de canje, este último se formaliza mediante el formato RevArq FP20 Canjes

Para aumentar su visibilidad y el impacto de los artículos, se envían a bases de datos y sistemas de indexación y resumen (SIR) y, asimismo, pueden ser consultados y descargados en la página web de la revista.

La Revista de Arquitectura no maneja cobros, tarifas o tasas de publicación de artículo (Article Processing Charge-APC), o por el sometimiento de textos a la publicación.

\section{(A) Ética y buenas prácticas}

La Revista de Arquitectura se compromete a cumplir y respetar las normas éticas en todas las etapas del proceso de publicación. Los autores de los artículos publicados darán cumplimiento a los principios éticos contenidos en las diferentes declaraciones y legislaciones sobre propiedad intelectual y derechos de autor específicos del país donde se realizó la investigación. En consecuencia, los autores de los artículos postulados y aceptados para publicar, que presentan resultados de investigación, deben firmar la declaración de originalidad (formato RevArq FP00 Carta de originalidad).

La Revista de Arquitectura reconoce y adopta los principios de transparencia y buenas prácticas descritos por COPE, "Principles of Transparency and Best Practice in Scholarly Publishing" (2015).

El equipo editorial tiene la obligación de guardar la confidencialidad acerca de los artículos recibidos, y abstenerse de usar en sus propias investigaciones datos, argumentos o interpretaciones hasta tanto el artículo no sea publicado. También debe ser imparcial y gestionar los artículos de manera adecuada y en los plazos establecidos. La selección de revisores se hará con objetividad y estos deberán responder a la temática del artículo.

El editor, los autores y los revisores deben seguir las normas éticas internacionales definidas por el Committee on Publication Ethics (COPE), con el fin de evitar casos de:

- Fabricación, falsificación u omisión de datos.

- Plagio y autoplagio.

- Publicación redundante, duplicada o fragmentada.

- Omisión de referencias a las fuentes consultadas.

- Utilización de contenidos sin permiso o sin justificación.

- Apropiación individual de autoría colectiva.

- Cambios de autoría.

- Conflicto de interés (CDI) no revelado o declarado.

- Otras que pudieran surgir en el proceso de investigación y publicación. La fabricación de resultados se genera al mostrar datos inventados por los autores; la falsificación resulta cuando los datos son manipulados y cambiados a capricho de los autores; la omisión se origina cuando los autores ocultan deliberadamente un hecho o dato. El plagio se da cuando un autor presenta como ideas propias datos creados por otros. Los casos de plagio son los siguientes: copia directa de un texto sin entrecomillar o citar la fuente, modificación de algunas palabras del texto, paráfrasis y falta de agradecimientos; el autoplagio se da cuando el mismo autor reutiliza material propio que ya fue publicado, pero sin indicar la referencia al trabajo anterior. La revista se apoya en herramientas digitales que detectan cualquiera de estos casos en los artículos postulados, y es labor de los editores y revisores velar por la originalidad y fidelidad en la citación. La publicación redundante o duplicada se refiere a la copia total, parcial o alterada de un trabajo ya publicado por el mismo autor

En caso de sospechar de alguna mala conducta se recomienda seguir los diagramas de flujo elaborados por COPE (2008), con el fin de determinar las acciones correspondientes.

La Revista de Arquitectura se reserva el derecho de retractación de publicación de aquellos artículos que, posterior a su publicación, se demuestre que presentan errores de buena fe, o cometieron fraudes o malas prácticas científicas. Esta decisión se apoyará en "Retraction Guidelines" (COPE, 2009). Si el error es menor, este se podrá rectificar mediante una nota editorial de corrección o una fe de erratas. Los autores también tienen la posibilidad de solicitar la retractación de publicación cuando descubran que su trabajo presenta errores graves. En todos los casos se conservará la versión electrónica y se harán las advertencias de forma clara e inequívoca.

\section{A Privacidad y manejo de la información.} Habeas Data

Para dar cumplimiento a lo previsto en el artículo 10 del Decreto 1377 de 2013, reglamentario de la Ley 1581 de 2012, y según el Acuerdo 002 del 4 de septiembre de 2013 de la Universidad Católica de Colombia, "por el cual se aprueba el manual de políticas de tratamiento de datos personales":

La Universidad Católica de Colombia, considerada como responsable o encargada del tratamiento de datos personales, manifiesta que los datos personales de los autores, integrantes de los comités y pares revisores, se encuentran incluidos en nuestras bases de datos; por lo anterior, y en cumplimiento de las disposiciones legales vigentes, la Universidad solicitará siempre su autorización, para que en desarrollo de sus funciones propias como Institución de Educación Superior, en especial las relacionadas con la docencia, la extensión y la investigación, la Universidad Católica de Colombia pueda recolectar, recaudar, almacenar, usar, circular, suprimir, procesar, intercambiar, compilar, dar tratamiento, actualizar, transmitir o transferir a terceros países y disponer de los datos que le han suministrado y que han sido incorporados en las bases de datos de todo tipo que reposan en la Universidad.

La Universidad Católica de Colombia queda autorizada, de manera expresa e inequívoca, en los términos señalados por el Decreto 1377 de 2013, para mantener y manejar la información de nuestros colaboradores (autores, integrantes de los diferentes comités y pares revisores); así mismo, los colaboradores podrán ejercer sus derechos a conocer, actualizar, rectificar y suprimir sus datos personales, para lo cual se han dispuesto las siguientes cuentas de correo electrónico: 
La Revista de Arquitectura (Bogotá) recibe artículos de manera permanente. Los artículos se procesan a medida que se postulan, dependiendo el flujo editorial de cada sección.

El idioma principal es el español, y como opcionales están definidos el inglés, el portugués y el francés; los textos pueden ser escritos y presentados en cualquiera de estos.

Los artículos postulados deben corresponder a las categorías universalmente aceptadas como producto de investigación, ser originales e inéditos y sus contenidos responder a criterios de precisión, claridad y brevedad.

Como punto de referencia se pueden tomar las tipologías y definiciones del Îndice Bibliográfico Nacional, Publindex (2010) que se describen la continuación:

1. Artículo de revisión: documento resultado de una investigación terminada donde se analizan, sistematizan e integran los resultados de investigaciones publicadas o no publicadas, sobre un campo en ciencia o tecnología, con el fin de dar cuenta de los avances y las tendencias de desarrollo. Se caracteriza por presentar una cuidadosa revisión bibliográfica de por lo menos 50 referencias.
2. Artículo de investigación científica y tecnológica: documento que presenta, de manera detallada, los resultados originales de proyectos terminados de investigación. La estructura generalmente utilizada contiene cuatro apartes importantes: introducción, metodología, resultados y conclusiones.

3. Artículo de reflexión: documento que presenta resultados de investigación terminada desde una perspectiva analítica, interpretativa o crítica del autor, sobre un tema específico, recurriendo a fuentes originales.

Adicional a estas tipologías, se pueden presentar otro tipo de artículos asociados a procesos de investigación-creación y/o investigación proyectual. En todos los casos se debe presentar la información suficiente para que cualquier investigador pueda reproducir la investigación y confirmar o refutar las interpretaciones defendidas y sea evidente el aporte a la disciplina.

En todos los casos se debe presentar la información suficiente para que cualquier investigador pueda reproducir la investigación y confirmar o refutar las interpretaciones defendidas.

\section{(A) Instrucciones para postular artículos}

Postular el artículo en la página web de la Revista de Arquitectura (Bogotá) y adjuntar comunicación escrita dirigida al editor RevArq_FP00 Carta de originalidad (debidamente firmada por todos los autores en original); de igual manera, se debe diligenciar el formato de hoja de vida RevArq FP01 Hoja de Vida (una por cada autor).

En la comunicación escrita el autor expresa que conoce y acepta la política editorial de la Revista de Arquitectura (Bogotá), que el artículo no está postulado para publicación simultáneamente en otras revistas u órganos editoriales y que no existe conflicto de intereses (ver modelo RevArq FP06 CDI) y que, de ser aceptado, concederá permiso de primera publicación, no exclusiva a nombre de la Universidad Católica de Colombia como editora de la revista.

Los artículos deben tener en cuenta las siguientes recomendaciones:

- En la primera página del documento se debe incluir:

Tírulo: no exceder 15 palabras

Subtítulo: opcional, complementa el título o indica las principales subdivisiones del texto.

Nombre del autor o autores: nombres y apellidos completos o según modelo de citación adoptado por el autor para la normalización de los nombres del investigador. Como nota al pie (máximo 100 palabras) formación académica, experiencia profesional e investigativa, código ORCID https://orcid.org/, e información de contacto, correo electrónico.

Filiación institucional: debajo del nombre se debe declarar la ins-titución en la cual se desarrolló el producto, de la cual recibió apoyo o aquella que respalda el trabajo investigativo.

Resumen: debe ser analítico, se redacta en un solo párrafo, da cuenta del tema, el objetivo, la metodología, los resultados y las conclusiones; no debe exceder las 150 palabras.

Palabras clave: cinco palabras o grupo de palabras, ordenadas alfabéticamente y que no se encuentren en el título o subtítulo; estas sirven para clasificar temáticamente al artículo. Se recomienda emplear principalmente palabras definidas en el tesauro de la Unesco (http://databases. unesco.org/thessp/), en el tesauro de Arte \& Arquitectura (C) (www.aatespanol.cl), o Vitruvio (http://vocabularyserver.com/vitruvio/)

También se recomienda incluir título, resumen y palabras clave en segundo idioma.

- La segunda página y siguientes deben tener en cuenta:

El cuerpo del artículo se divide en: Introducción, Metodología, Resultados y Discusión de resultados; posteriormente se presentan las Conclusiones, y luego las Referencias bibliográficas y los Anexos (modelo IMRYD). Las tablas y figuras se deben incorporar en el texto.

Descripción del proyecto de investigación: en la introducción se debe describir el tipo de artículo y brevemente el marco investigativo del cual es resultado y diligenciar el formato (RevArq FP02 Info Proyectos de Investigación).

TEXTO: todas las páginas deben venir numeradas y con el título de artículo en la parte superior de la página. Márgenes de $3 \mathrm{~cm}$ por todos los lados, interlineado doble, fuente Arial o Times New Roman de 12 puntos, texto justificado (Ver plantilla para presentación de artículos). La extensión de los artículos debe ser de alrededor de 5.000 palabras ( \pm 20 páginas, incluyendo gráficos, tablas, referencias, etc.); como mínimo 3.500 y máximo 8.000 palabras. Se debe seguir el estilo vigente y recomendado en el Manual para Publicación de la American Psychological Association (APA). (Para mayor información véase http://www.apastyle.org/)
Citas y notas al pie: las notas aclaratorias o notas al pie no deben exceder cinco líneas o 40 palabras, de lo contrario estas deben ser incorporadas al texto general. Las citas pueden ser:

Corta: (con menos de 40 palabras) se incorporan al texto y pueden ser: textuales (se encierran entre dobles comillas), parafraseo o resumen (se escriben en palabras del autor dentro del texto).

Cita textual extensa: (mayor de 40 palabras) debe ser dispuesta en un renglón y un bloque independiente con sangrías y omitiendo las comillas, no olvidar en ningún caso la referencia del autor (Apellido, año, página).

Referencias: como modelo para la construcción de referencias se emplea el estilo recomendado en el Manual para Publicación de la American Psychological Association (APA) (http://www.apastyle.org/).

Siglas: en caso de emplear siglas en el texto, las figuras o las tablas, se debe proporcionar la equivalencia completa la primera vez que se empleen y encerrarlas entre paréntesis. En el caso de citar personajes reconocidos se deben colocar nombres o apellidos completos, nunca emplear abreviaturas.

Figuras y tablas: las figuras (gráficos, diagramas, ilustraciones, planos, mapas o fotografías) y las tablas deben ir numeradas y contener título o leyenda explicativa relacionada con el tema del artículo, que no exceda las 15 palabras (Figura 1. xxxxx, Tabla 1. xxxx, etc.) y la procedencia (fuente: autor o fuente, año, página). Estas se deben referenciar en el texto de forma directa o entre paréntesis; se recomienda hacerlo con referencias cruzadas.

También se deben entregar en medio digital, independiente del texto, en formatos editables o abiertos. La marcación de los archivos debe corresponder a la incluida en el texto. Según la extensión del artículo se deben incluir de 5 a 10 gráficos. Ver guía para la búsqueda de imágenes de dominio público o bajo licencias Creative Commons (CC).

El autor es el responsable de adquirir los derechos o las autorizaciones de reproducción a que haya lugar para imágenes o gráficos tomados de otras fuentes, así como de entrevistas o material generado por colaboradores diferentes a los autores; de igual manera, se debe garantizar la protección de datos e identidades para los casos que sea necesario.

FotografíA: pueden ser entregadas en original para ser digitalizadas, de lo contrario se deben digitalizar con una resolución igual o superior a 300 dpi para imágenes a color y 600 para escala de grises. Los formatos de las imágenes pueden ser TIFF, PSD o JPG, y deben cumplir con las características expresadas en el punto anterior (figuras).

Planimetría: se debe entregar la planimetría original en medio digital, en lo posible en formato CAD, y sus respectivos archivos de plumas o en PDF; de no ser posible, se deben hacer impresiones en tamaño carta con las referencias de los espacios mediante numeración y lista adjunta. Deben tener escala gráfica, escala numérica, norte, coordenadas y localización. En lo posible, no deben contener textos, achurados o tramas.

Para más detalles, consultar el documento RevArq Parámetros para Autores Descripción en el portal web de la Revista de Arquitectura (Bogotá)

\section{Beneficios}

Como reconocimiento a los autores, se les hará envío postal de dos ejemplares de la edición impresa sin ningún costo y entregada en la dirección consignada en el formato de hoja de vida (RevArq FP01); adicionalmente, se enviará el vínculo para la descarga de la versión digital.

También se enviará una constancia informativa en la que se relaciona la publicación del artículo y, de manera opcional, se pueden detallar las fechas del proceso editorial y el arbitraje realizado. 
La selección de revisores se realiza de acuerdo con los siguientes criterios:

- Afinidad temática.

- Formación académica.

- Experiencia investigativa y profesional.

- Producción editorial en revistas similares o en libros resultado de investigación.

El proceso de arbitraje se basa en los principios de equidad e imparcialidad, y en los criterios de calidad y pertinencia.

El desarrollo de la revisión se realiza según el formato (RevArq FP10 Evaluación de artículos) y las observaciones que el revisor considere necesarias en el cuerpo del artículo. En cualquiera de los conceptos que emita el revisor (Aceptar, Publicable con modificaciones, Reevaluable o No publicable), y como parte de la labor formativa y de comunidad académica, el revisor hará sugerencias para mejorar et documento. El revisor podrá solicitar una nueva relectura del artículo después de los ajustes realizados por el autor.

El revisor también deberá diligenciar el formato RevArq FP01 Hoja de Vida, con el fin de certificar y soportar el proceso de revisión ante los SIR que así lo soliciten.

En el proceso de arbitraje se emplea el método doble ciego, los nombres del revisor no serán conocidos por el autor y viceversa. Con el fin de garantizar el anonimato del autor, al artículo postulado se le han podido suprimir nombres, instituciones o imágenes que puedan ser asociadas de manera directa al autor.

Aunque se procura el anonimato, una vez recibida la invitación como par revisor del artículo, el revisor debe cerciorarse de que no exista conflicto de intereses (CDI) o alguna limitante que afecte la revisión o que pueda ser vista como tal (lazos familiares, amistad o enemistad, vínculos contractuales o laborales, posiciones éticas, etc.), de presentarse esta situación se notificara al editor. (Ver modelo RevArq FP06 CDI).

Dada la confidencialidad del proceso de revisión, y considerando los derechos de autor y de propiedad intelectual que pueda haber sobre el material que se entrega, el revisor se compromete a mantener en absoluta reserva su labor, a limitar el uso de la obra entregada solo para el propósito designado y a devolver la documentación remitida una vez concluya la actividad.

El tiempo establecido para las revisiones de pares es de máximo un mes a partir de la confirmación de la recepción de la documentación. Ese plazo podrá ser modificado de mutuo acuerdo entre e editor y el revisor, siempre y cuando no afecte la periodicidad de la revista, la impresión o el tiempo para emitir una respuesta al autor.

Los revisores se acogerán a "COPE Ethical Guidelines for Peer Reviewers" de COPE.

\section{Beneficios}

Como retribución a los revisores se les hará envío postal de un ejemplar de la edición impresa sin ningún costo y entregada en la dirección consignada en el formato de hoja de vida. También, si es de interés para el revisor, podrá hacer la solicitud de alguna de las publicaciones editadas y presentes en el catálogo de publicaciones de la UNIVERSIDAD CATÓLICA DE COLOMBIA, previa aprobación de la Editorial y sujeto a la disponibilidad.

Si lo desea tendrá derecho a una constancia de la colaboración en la revisión de artículos, la cual solo contendrá el periodo en el cual se realizó la actividad. También tendrá la posibilidad de aceptar o no la publicación de su nombre, nacionalidad y nivel máximo de formación en la página web de la Revista de Arquitectura (Bogotá) en su calidad de colaborador.

\section{A Proceso de revisión por pares}

Luego de la postulación del artículo, el editor de la Revista de Arquitectura (Bogotá) selecciona y clasifica los artículos que cumplen con los requisitos establecidos en las directrices para los autores. El editor podrá rechazar en primera instancia artículos, sin recurrir a un proceso de revisión, si los considera de baja calidad o por presentar evidencias de faltas éticas o documentación incompleta.

Los artículos se someterán a un primer dictamen del editor, de los editores de sección y del Comité Editorial, teniendo en cuenta:

- Afinidad temática, relevancia del tema y correspondencia con las secciones definidas.

- Respaldo investigativo.

- Coherencia en el desarrollo del artículo, así como una correcta redacción y ortografía.

- Relación entre las figuras y tablas con el texto del artículo.
En esta revisión se verificará el nivel de originalidad mediante el uso de software especializado (Ithenticate o similar) y recursos digitales existentes para tal fin, también se observará la coherencia y claridad en los apartados del documento (modelo IMRYD), la calidad de las fuentes y la adecuada citación, esto quedará consignado en el formato (RevArq FP09 Revisión de artículos); esta información será cargada a la plataforma de gestión editorial y estará a disposición del autor.

En caso de que el artículo requiera ajustes preliminares, será devuelto al autor antes de ser remitido a revisores. En este caso, el autor tendrá veinte días para remitir nuevamente el texto con los ajustes solicitados.

Después de la preselección se asignan mínimo dos revisores especializados, quienes emitirán su concepto utilizando el formato (RevArq FP10 Evaluación de artículos) y las anotaciones que consideren oportunas en el texto; en esta etapa se garantizará la confidencialidad y el anonimato de autores y revisores (modalidad doble ciego).

Del proceso de revisión se emite uno de los siguientes conceptos que será reportado al autor:

\section{- Aceptar el envío: con o sin observaciones.}

- Publicable con modificaciones: se podrá sugerir la forma más adecuada para una nueva presentación, el autor puede o no aceptar las observaciones según sus argumentos. Si las acepta, cuenta con quince días para realizar los ajustes pertinentes.

- Reevaluable: cumple con algunos criterios y debe ser corregido. Es necesario hacer modificaciones puntuales y estructurales al artículo. En este caso, el revisor puede aceptar o rechazar hacer una nueva lectura del artículo luego de ajustado.

- No publicable: el autor puede volver a postular el artículo e iniciar nuevamente el proceso de arbitraje, siempre y cuando se evidencien los ajustes correspondientes.

En el caso de presentarse diferencias sustanciales y contradictorias en los conceptos sobre la recomendación del revisor, el editor remitirá el artículo a un revisor más o a un miembro del Comité Editorial quien podrá actuar como tercer árbitro, con el fin de tomar una decisión editorial sobre la publicación del artículo.

Los autores deberán considerar las observaciones de los revisores o de los editores, y cada corrección incorporada u omitida debe quedar justificada en el texto o en una comunicación adjunta. En el caso que los autores omitan las indicaciones realizadas sin una argumentación adecuada, el artículo será devuelto y no se dará por recibido hasta que no exista claridad al respecto.

El editor respetará la independencia intelectual de los autores y a estos se les brindará el derecho de réplica en caso de que los artículos hayan sido evaluados negativamente y rechazados.

Los autores, con su usuario y contraseña, podrán ingresar a la plataforma de Gestión Editorial, donde encontrarán los conceptos emitidos y la decisición sobre el artículo.

El editor y el Comité Editorial se reservan el derecho de aceptar o no la publicación del material recibido. También se reservan el derecho de sugerir modificaciones de forma, ajustar las palabras clave o el resumen y de realizar la corrección de estilo. El autor conocerá la versión final del texto antes de la publicación oficial del mismo.

Cuando un artículo es aceptado para su publicación, el autor debe firmar la autorización de reproducción (RevArq FP03 Autorización reproducción). Para más información ver: Política de derechos de autor

\section{Notas aclaratorias:}

La Revista de Arquitectura (Bogotá) busca el equilibrio entre las secciones, motivo por el cual, aunque un artículo sea aceptado o continúe en proceso de revisión, podrá quedar aplazado para ser publicado en un próximo número; en este caso, el autor estará en la posibilidad de retirar la postulación del artículo o de incluirlo en el banco de artículos del próximo número.

El editor y los editores de sección de la Revista de Arquitectura (Bogotá) son los encargados de establecer contacto entre los autores y revisores, ya que estos procesos se realizan de manera anónima.
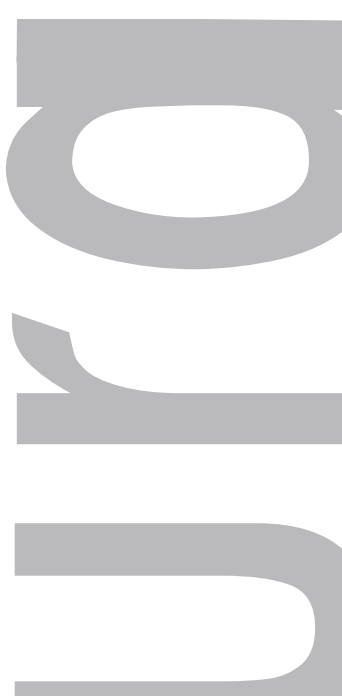
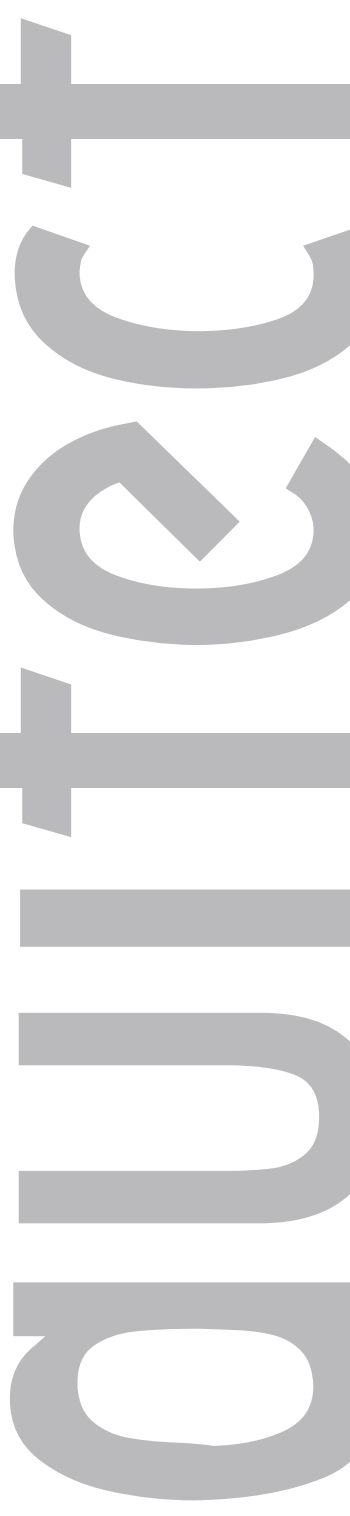

Vol. 


\section{Índice de caminabilidad para la ciudad de Bogotá \\ $\infty \quad$ Walkability index for the city of Bogotá \\ ن Índice de caminhabilidade para a cidade de Bogotá \\ Julián Alberto Gutiérrez-López \\ Yolanda Beatriz Caballero-Pérez
Rubén Alejandro Escamilla-Triana}

Principios, criterios y propósitos de desarrollo sustentable para la $\bar{\Upsilon}$ redensificacion en contextos urbanos informales

Principles, criteria and purposes of sustainable development for

re-densification in unplanned urban context

Princípios, critérios e propósitos de desenvolvimento sustent

Fabián Adolfo Aguilera-Martínez

Fabián Alonso Sarmiento-Valdés

Complejidad y constructivismo en la nueva tradición de la arquitectura de la posguerra

Complexity and constructivism in the new tradition of post-war architecture

U Complexidade e construtivismo na nova tradição da arquitetura do pósguerra

Francisco Javier Fuentes-Farías

Conservación del arte contemporáneo. El caso de Mathias Goeritz en la Catedral Metropolitana de México

Conservation of contemporary art: The case of Mathias Goeritz in the

$\varangle \quad$ Metropolitan Cathedral of Mexico

Conservação da arte contemporânea: o caso de Mathias Goeritz na Catedral Metropolitana do México

\section{Alberto Cedeño-Valdiviezo}

Pablo Torres-Lima

Operando desde la forma: un procedimiento para la valoración de la vivienda colectiva

On Operating based on form: A procedure for the valuation of collective housing

U Operando a partir da forma: um procedimento para avaliar a moradia coletiva

\section{Julián Camilo Valderrama-Vidal}

Disponibilidad de las técnicas constructivas de habitación en

ن Availability of timber housing construction techniques in Brazil

U. Disonibilidade das técnicas construtivas de moradia em madeira no Brasil

\section{Victor A. De Araujo}

Carlos M. Gutiérrez-Aguilar

Juliana Cortez-Barbosa

Maristela Gava

losé N. Garcia

Diseño y construcción de un paraguas plegable

Design and construction of a folding umbrella for architectural spaces

ن Desenho e construção de um guarda-chuva dobrável para espaços arquitetônicos

Carlos César Morales-Guzmán

Envolventes eficientes. Relación entre condiciones ambientales, espacios confortables y simulaciones digitales

(j) Efficient building envelopes: Relationship between environmental conditions,

U. comfortable spaces, and digital simulations

Envolventes eficientes: relação entre condições ambientais, espaços confortáveis e simulações digitais

Natalia Medina-Patrón

Jonathan Escobar-Saiz

(Re)pensando el enfoque tecnológico: el caso del Centro

Experimental de la Vivienda Económica (CEVE) en Argentina

ㅇ $(\mathrm{Re})$ thinking the technological approach: The case of the Experimental Center

으 for Economic Housing (CEVE) in Argentina

ن (Re)pensando a abordagem tecnológica. O caso do Centro Experimental da

Moradia Econômica na Argentina

Gustavo Pelegrin

Laila Fleker

Aurelio Ferrero 